Archimer, archive institutionnelle de l'Ifremer Vol. 259, Issues 1-4, 8 September 2006, P. 415-423 http://www.ifremer.fr/docelecl http://dx.doi.org/10.1016/i.aquaculture.2006.05.018 (C)2006 Elsevier

\title{
Investigation of marine bivalve morphology by in vivo MR imaging: First anatomical results of a promising technique
}

\author{
Stéphane Pouvreau ${ }^{\underline{a}}$, Marc Rambeau ${ }^{\underline{\underline{b}}}$, Jean Claude Cochard ${ }^{\underline{\underline{a}}}$ and René Robert ${ }^{\underline{\underline{a}}}$
}

\begin{abstract}
aFREMER, Department of Marine Animal Ecophysiology and Physiology, Argenton Experimental Laboratory, 11 , Presqu'île du Vivier, 29840 Argenton en Landunvez, France

${ }^{\mathrm{b}}$ Department of Radiology and biomedical imaging, South Hospital, 16, bd de Bulgarie, BP 90347, 35203 Rennes cedex 2, France
\end{abstract}

*: Corresponding author : spouvreau@ifremer.fr

\begin{abstract}
Classically, investigation of the internal morphology and composition of molluscs and especially bivalves relies on destructive method (biometry, biochemistry and histology). These techniques have given essential information, but in contrast are time consuming and lead to the irreversible loss of the animal while they don't allow integration of the various levels of molecular-toorganism functioning. The aim of this study is to analyze for the first time the potential of NMR (nuclear magnetic resonance) imaging (MRI) to depict, with sufficient resolution and satisfactory contrast, the anatomy of a bivalve model, the Pacific oyster, Crassostrea gigas, without opening it.
\end{abstract}

MRI experiments were carried out at $19{ }^{\circ} \mathrm{C}$ in several non-anaesthetized adult Pacific oysters, analyzed individually in a standard General Electric Signa 1.5T (whole body) instrument with actively shielded gradient coils $(23 \mathrm{mT} / \mathrm{m})$. To enhance signal detection, the oyster was centered in the middle of a 12-cm diameter Helmholtz-like radio-frequency coil (medical wrist coil). After several trials, the best MRI acquisition sequence retained was a T1-weighted procedure (spoiled gradient echo sequence) through two orthogonal directions (transversal and sagittal sections). According to direction, MR parameters were as follows: TR $=200-400 \mathrm{~ms}, \mathrm{TE}=4-5 \mathrm{~ms}, \mathrm{FOV}=120 \times 90 \mathrm{~mm}$, matrix $=512 \times$ 256 units, 6 signal averages per echo, spatial resolution $=230 \mu \mathrm{m}$, total scan time $=3-6 \mathrm{~min}$.

The MR images obtained have satisfactory contrast-to-noise levels, and depict with a sufficient resolution all the main organs in the soft tissues of the oyster. Comparison with histology-based anatomical information shows that the MR images faithfully represent some detailed anatomical structures of Pacific oysters. Potential applications in shellfish aquaculture are reported, and perspectives are given which constitute starting point from furthers studies

Keywords: Pacific oyster; MRI; Anatomy; Aquaculture; In vivo physiology 


\section{Introduction}

Marine bivalves and especially the Pacific oyster, Crassostrea gigas, are economically important in the French aquaculture. Its production has become a major industry with a production above 100000 metric tons in 2002. A quarter of this production relies on spat produced in hatcheries. Nevertheless, the physiology of this bivalve is not well known and control of its reproduction in hatcheries is empirically based. To increase knowledge on this species and improve hatchery techniques, it appears obvious that new tools and/or approaches need to be developed.

Classically, the investigation of soft tissue in marine molluscs and especially in marine bivalves relies on destructive methods, since a shell completely encloses the animal. Anatomical structures are generally studied after removing the shell, followed by dissection by mean of histologic serial sections generally with a resolution of 4-5 $\mu \mathrm{m}$ (e.g. Chavez et al., 2002). The evolution of gametogenesis can be quantitatively assessed with the help of image analysis (e.g. Enriquez-Diaz et al., 2003, Fabioux et al., 2005). Analysis of physiological or biochemical changes within tissues necessarily involves the sacrifice of specimens as well as the preparation and analysis of numerous samples. These standard techniques give valuable information but are inconvenient for two main reasons that may be limiting in specific studies: these methods are (1) very time consuming and (2) necessarily destructive. Therefore, the development of noninvasive and quantitative procedures are needed to achieve a deeper understanding of biochemical and physiological adaptations in shelled animals.

Non-invasive methods can also be applied for production applications. For oyster farming and especially hatchery production, the potential applications of non-invasive procedures could be numerous, for example: (1) to identify the meat quality of broodstock when they enter the hatchery (e.g. Toussaint et al., 2005 for fishes); (2) to follow very easily gonadal evolution during broodstock conditioning; (3) to identify the sex of broodstock oysters before fertilization and crossbreeding; and (4) to provide a quality indication for oocytes and spermatozoa (see Hagedorn et al., 1997). Among the various non-invasive imaging methods and after preliminary trials, NMR (Nuclear Magnetic Resonance) imaging (MRI) appears to be a promising way to reach such objectives.

There are several studies dealing with investigation by MRI for land or freshwater invertebrates (e.g. Jasanoff and Sun, 2002; Wecker et al., 2002), and a few reports concerning marine fishes and invertebrates (e.g. Bock et al., 2001; Bock et al., 2002; Mark et al., 2002; Toussaint et al., 2005), but no work on marine bivalves to our knowledge.

To complement these studies, the aim of the present work was (1) to provide the first NMR imaging results for Pacific oysters, (2) to depict their anatomy with optimal MR parameters and (3) to show the feasibility and the potentialities of this technique for further investigations in marine biology and as a practical hatchery tool.

\section{Materials and methods}

\section{Animal origin and preparation}

Adult Pacific oysters (shell length ca. 11-12 cm, approx. 150 g, 3 years old) came from Aber Benoît River (North Brittany, France). They were collected during spring 2001 and kept in aquaculture facilities of the IFREMER shellfish laboratory located in Argenton near Brest (France) under controlled conditions (food level, temperature, salinity) similar to their natural habitat. They were periodically brought to the department of radiology and biomedical imaging (Rennes South Hospital , France) for the NMR imaging procedure. No anaesthetics were employed and all animals survived normally after the procedure. 


\section{Nuclear Magnetic Resonance Imaging procedure}

All MR images were performed on a standard General Electric Signa $1.5 \mathrm{~T}$ (whole body) imager with actively shielded gradient coils $(23 \mathrm{mT} / \mathrm{m})$. To enhance signal detection, the oyster was centered in the middle of a 12-cm diameter Helmholtz-like radio-frequency coil (medical wrist coil).

The images described here were acquired at ambient temperature (ca. 18-20 ${ }^{\circ} \mathrm{C}$ ) using a spoiled gradient echo sequence (SPGR-sequence) manipulated to produce intensity maps of water and lipid proton densities (T1-weighted procedure) through selected planes of the specimen with an optimal signal-to-noise ratio (SNR). Slices were selected in two orthogonal directions (transversal and sagittal) and the slice thickness was $3 \mathrm{~mm}$ without slice separation. According to direction, MR parameters were as follows: echo time (TE) was around 4-5 ms, relaxation delays (TR) varied between $200-400 \mathrm{~ms}$, the bandwidth was set to $15.6 \mathrm{kHz}$, the flip angle around $80^{\circ}$. Matrix and field of view (FOV) were equal to 512 x 256 units and 120 x $90 \mathrm{~mm}$, respectively, leading to a minimal resolution of $230 \mu \mathrm{m}$. The number of sections imaged per oyster varied between 10 and 22 according to the direction. The total scan time varied from 3 to 6 min according to the number of slices. The NMR images were actively contrasted during this procedure. The degree of brightness in each image was proportional to the concentration of protons and their respective relaxation properties: tissues with high lipid content are clearly revealed as bright areas whereas tissues having a high water content appear as dark areas. Gray level of pixels in each image was evaluated using image $\mathrm{J}$ software (developed by the National Institute of Health , USA). The values range from 0 (black color) to 255 (white color).

\section{Histological analysis}

One oyster was chosen among those used in MRI experiments. Its shell was opened and soft tissues, i.e. total flesh, were removed from the shell, drained 5-min on absorbent paper and weighed to the nearest $0.1 \mathrm{~g}$. The flesh was then dissected to separate the adductor muscle, the gills and the 'visceral mass' (the gonad of $C$. gigas is fused with digestive gland to form a complex organ called 'visceral mass'). For histological examination, 3-mm cross sections were sampled from the visceral mass realised in anterior to the pericardial region and immediately fixed in Davidson's solution (Shaw and Battle, 1957) at $4^{\circ} \mathrm{C}$ for at least 48 hours. Sections were then dehydrated in ascending ethanol solutions, cleared with xylene and embedded in paraffin. Five- $\mu \mathrm{m}$ sections were cut, mounted on glass slides, stained with Harris's hematoxylin-Eosin Y (Martoja and Martoja-Pierson, 1967) and coverslipped. Digital images of the sections were acquired at several magnifications using a light microscope.

\section{Results}

In general, all images were highly contrasted with a resolution accurate enough to differentiate organs and structures. The oyster appeared to be non-sensitive to the acoustic vibrations from the gradient coils since no movement artifacts were observed over the time course of image acquisition. Measurements were performed in air, but no significant artifacts associated with the gradients at the interfaces between object and air were observed. Nevertheless, some air bubbles were detected inside the shell cavity and led to some small artifacts on the image.

Figure 1 represents a MR image obtained in the sagittal direction. Shell (at the periphery of the soft tissue) is not well defined. In contrast, image clearly reveal the soft tissue of the oyster and distinguish among three principal components: the gills and mantle (ventral and posterior side), the adductor muscle (central part) and the visceral mass (anterior side). Figure 2 represents a stacked series of anatomical MR images obtained in the sagittal direction from the left (cupped valve) to the right side (flat valve) of the oyster. 
The mantle is a thin organ that is easiest to observe in the frontal direction (see below) but can nevertheless be located at the outer limit of the soft tissues, especially near the hinge (mantle isthmus, Fig. 2e). The gills also have a fine structure that appears in low gray level on the MR images (ca. 80) and are accordingly not well contrasted with the shell cavity. Nevertheless, their filamentous structure can be clearly observed (Fig. 1, 2e).

The adductor muscle appears clearly in medium gray level (ca. 120). The resolution is good enough to show a main hemolymph vessel (Fig. 1).

In the visceral mass, the main organs are discernible: the labial palps, the digestive gland, the diffuse gonad, the digestive tract and the pericardial cavity (Fig. 1). The labial palps that appear in medium gray level (ca. 120) fuse with the visceral mass, especially with the digestive gland. This latter organ is dispersed around the stomach and appears in medium gray level (ca. 150) in contrast with the stomach (ca. 100) and the gonad (ca. 195). The gonad is the brightest organ, easily distinguishable as a diffused layer at the periphery of the visceral mass (Fig. 1). The digestive tract consists of a complicated 3-D structure and is consequently difficult to analysis on a 2-D plane. The detailed sagittal plane image (Fig. 1) shows the short esophagus, the stomach, the crystalline style sac, parts of the intestine and the rectum. The 3$\mathrm{D}$ organization of the intestine can be observed on several slices in Fig. 2 since it contrasts clearly with the adjacent organs (gray level of ca. 90). After leaving the stomach (Fig. 2e), the initial section of the intestine (i.e. the mid-gut or dorsal part) first goes posteriorly to the pyloric process. The middle or ventral compartment of the intestine curves ventrally and goes back along the style sac. Then, it runs dorsally (Fig. $2 \mathrm{f}$ and g) and circles the left part of the stomach (the style sac intestinal cross, Fig. 2c). Then the rectal compartment of the intestine goes back dorsally again by passing near the pericardial cavity (Fig. 2e) and finally ends as a rectum near the adductor muscle (Fig. $2 \mathrm{f}$ and g). The pericardial cavity with a mean gray level of ca. 62 is well contrasted in comparison with the adjacent organs. It extends from digestive gland to adductor muscle and is rounded in shape. The internal compartment of the pericardial cavity, and especially the ventricle (anterior side) and the two auricles (posterior side) are not discernable on the images. Nevertheless, at the anterior end of the pericardial cavity, the aorta can be observed to enter in the ventricle area (Fig. 2f). And at the posterior end of the pericardial cavity, the auricles are connected to branched hemolymph vessels coming from the adductor muscle.

Some anatomical details are easier to observe in frontal section (Fig. 3 and 4). These show some details in the structure of the shell, especially chambers caused by the polychaete worm Polydora sp. and larger cavities filled with mud and water. The frontal section at the level of the pericardial cavity (Fig. 3) shows clearly the thin structures of the mantle lobes and the gills. The resolution is sufficient to clearly distinguish the four thin demibranchs (regrouped in two ctenidia) of the gill (Fig. 3 and 4f,g,h). The left and right auricles appear as two rounded thin structures inside the pericardial (Fig. 3 and 4f). On the each side of the pericardial cavity (Fig. 3 and 4f), the bright rounded structures of the gonad appear distinctly and show in their center the digestive tract (intestine compartment, style crystalline sac and rectum).

A comparison between a standard histological section and NMR imaging showed good correlation (Fig. 5). The resolution was higher on the microscopic image but each organ observed in detail on this image could be easily detected on MR image, even a structure as small as the aorta. 


\section{Discussion \\ Practical aspects}

The use of non-invasive imaging methods (MRI and X-ray computerized tomography) has been investigated to depict anatomic traits in different animal species since the beginning of the 1990s. As MRI scanners become more accessible for biological researchers, MR imaging and spectroscopy experiments are now feasible to study metabolism and organ functions in organisms other than typical medical animal models (e.g. Bock et al., 2002). Nowadays, there are several works dealing with investigation by MRI in freshwater species (e.g. Toussaint et al., 2005; Linden et al., 2001; Hagedorn et al., 1997; Seri et al., 1995; Van den Berg et al., 1995), but very few works in marine fishes and invertebrates (e.g. Bock et al., 2002; Mark et al., 2002; Bock et al., 2001). Indeed, compared to freshwater animals, the application of NMR techniques to marine organisms although feasible, is complicated by the electrical properties of seawater, where the high ion content causes inductive loss of signal intensity (i.e. reduction in the signal-to-noise ratio). To our knowledge, the present study constitutes the first morphological investigation of a marine bivalve by in vivo MR imaging. The anatomical results provided here indicate that MRI is a promising technique to investigate in vivo anatomic traits but also in vivo physiology in marine bivalves, especially in oysters.

Our results indicate that the oyster constitutes a particularly suitable model for employing MRI to study marine organisms: (1) it is an intertidal animal that endures prolonged emersion without problem and thus can be analyzed out of seawater in the imager, (2) its gonad is generally rich-in lipids easily detectable with MR imager, (3) oysters are easy to immobilize and internal movements while the shell is closed are nearly nonexistent, allowing long acquisition times for high resolution images without any blurring effects. This last point constitutes effectively a limiting factor when studying anatomy in small living animals (e.g. Goodman et al., 1995), for which anesthetics are often required.

Since oyster can be analyzed out of seawater in the imager, manipulation of specimens is simplified. Nevertheless, it is possible to carry out similar approaches with organisms immersed in water : for example, using MRI, van den berg et al. (1995) visualized directly the water flow in a breathing carp and Bock et al. (2001) followed ventilation and haemolymph circulation in marine spider crabs in a flow-through chamber inside a MR scanner.

This first study of a marine bivalve showed also that the effects due to field changes between shell, soft tissues and air were insignificant in oysters in this $1.5 \mathrm{~T}$ instrument (opposed to Wecker et al., 2002 for example). The only artifacts in oysters NMR images arose from some air bubbles inside the shell. This problem can be overcome by immersing oysters in seawater during half an hour just prior to MRI procedure.

\section{MR images}

The quality of the first MR images provided in this study is suitable for identifying internal structures of oysters within their shell (e.g. Evseev et al., 1995): the adductor muscle, the heart, the digestive system, the gonads as well as the gills could be easily identified without any problem. The correlation with histology was high: comparison of the MR and conventional microscopy images indicates that the main structures and organs in the soft tissues of oysters are very well represented by $1.5 \mathrm{~T}$ MRI. Of course, a more acute correlation will be presumably found by using higher resolution imaging by mean of the higher field imager (4.7 T or more), but accessibility to such imager is more restricted. On the other hand, using low-field imager $(0.1 \mathrm{~T})$, it is also possible to obtain general information on the condition of oyster (relative amount of intra-shell space occupied, as well as overall lipid and water content). This study demonstrates that non invasive and quantitative biometry in oysters is technically possible. Further, since MR imaging in principle allows the recording of 3D 
data sets, sections in all direction are possible and 3D reconstruction of the internal structure may contribute to a very comprehensive view of the anatomy of oyster.

Routine application will depend on the cost of MRI instruments. Although still expensive, the price of MR imagers is decreasing because of the development of smaller MR instruments dedicated to small animals. Several commercial companies have developed systems of measurement using magnetic resonance technologies for the control of humidity or fat in processed materials. These are portable systems costing less than $\$ 50,000$ and dedicated to industrial applications. They do not provide images, just certain information on the sample. But they would be sufficient for rapidly and non-destructively assessing certain characteristics of oyster broodstock, including lipid (eggs) and water content.

As a consequence and on the basis of these first results, the potential applications of MRI could be numerous. For example, in bivalve hatcheries, it would be possible, without sacrificing the oyster, to (1) identify individually the condition of broodstock when they enter the hatchery (the fraction of the intrashell volume occupied by soft tissue); (2) follow very easily and individually gonadal evolution during broodstock conditioning (lipid content); (3) identify sex of broodstock oysters (before fertilization and crossbreeding) because of the differential biochemical composition between ovary and testis (Li et al., 2000; Davenel et al., 2006); (4) give quality indicator of oocytes and spermatozoa crossbreeding and/or cryopreservation (e.g. Hagedorn et al., 1997). In the pearl industry, MR imaging would also be useful to understand and follow pearl development in a more informative way than with Xray imaging. In fish aquaculture, MR imaging has begun to be used to measure body composition (e.g. Toussaint et al., 2005).

On a more basic level, there are numerous possible uses of MRI to study bivalve physiology. Firstly, it should be possible to depict precisely the anatomy of oysters at higher resolution ( $<100 \mu \mathrm{m}$ sections) with the help of higher field imagers (4.7 T for example) in order to build a numerical anatomic atlas of the Pacific oyster and also to generate detailed images at near cellular resolution (e.g. Jasanoff and Sun, 2002). Secondly, it may be possible to employ this technique for future investigation of in vivo metabolism by ${ }^{1} \mathrm{H}$ and ${ }^{31} \mathrm{P}$ spectroscopy in bivalves, which would provide in vivo measurements of acid-base and energy status, (e.g. Sokolova et al., 2000; Mark et al., 2002; Bailey et al., 2004).

In conclusion, application of MR imaging is possible in marine bivalves, especially in oysters, with sufficient spatial resolution to depict anatomy without movements artifacts or magnetic susceptibilities. New MR instruments dedicated for animal studies would provide excellent tools for marine biological studies at all levels, ranging from ecology to physiology, as a complement to standard physiological and biochemical methods.

\section{Acknowledgements}

The study was supported by a specific grant from the Scientific Direction of IFREMER. We also thanks Dr Susan Ford for English revisions and improvements of the manuscript. 


\section{References}

Bailey, DM., Peck, LS., Bock, C., Pörtner, HO., 2004. High energy phosphate metabolism during exercise and recovery in Temperate and Antarctic scallops: an in vivo ${ }^{31} \mathrm{P}-\mathrm{NMR}$ study, Physiological and biochemical zoology 76, 622-633.

Bock, C., Frederich, M., Wittig, R.M., Pörtner, H.O., 2001. Simultaneous observations of haemolymph flow and ventilation in marine spider crabs at different temperatures: a flow weighted MRI study. Magn. Reson. Imaging 19, 1113-1124.

Bock, C., Sartoris, F.J., Pörtner, H.O., 2002. In vivo MR spectroscopy and MR imaging on non-anaesthetized marine fish: techniques and first results. Magn. Reson. Imaging 20, 165172.

Chavez-Villalba, J., Pommier, J., Andriamiseza, J., Pouvreau, S., Barret, J., Cochard, J.C., Le Pennec, M., 2002. Broodstock conditionning of the oyster Crassostrea gigas: origin and temperature effect. Aquaculture 214, 115-130.

Davenel, A., Quellec, S., Pouvreau, S., 2006. Non-invasive characterization of the gonadal development and sex of the Pacific oyster Crassostrea gigas by MRI. J. Magn. Res. Imaging, in press

Enriquez-Diaz, M., Pouvreau, S., Fabioux, C., Le Coguic, Y., Cochard, JC., Le Pennec, M., 2003. Reproductive strategy: Variability of reproductive pattern in two populations genetically determined of Crassostrea gigas. J. Shellfish Res. 22, pp. 328

Evseev, G.A., Yakovlev, Y.M., Li, X., 1996. The anatomy of the Pacific Oyster, Crassostrea gigas, (Thurnberg) (Bivalvia:ostreidae). Publ. Seto Mar. Biol. 37, 239-255.

Fabioux, C., Huvet, A., Le Souchu, P., Le Pennec, M., Pouvreau, S., 2005. Temperature and photoperiod drive Crassostrea gigas reproductive internal clock. Aquaculture 250, 458-470.

Goodman, BA., Gordon, S.C., Chudek, J.A., Hunter G., Woodford J.A.T., 1995. Nuclear Magnetic Resonance Micoscopy as a non-invasive tool to study the development of Lepidopteran pupae. J. Insect. Physiol. 41, 419-424.

Hagedorn, M., Hsu, E., Kleinhans, F.W., Wildt, 1997. New approaches for studying the permeability of fish embryos: Toward successful cryopreservation. Cryobiology 34, 335-347.

Jasanoff, A., Sun, P., 2002. In vivo magnetic resonance microscopy of brain structure in unanesthetized flies. J. Magn. Reson 158, 79-85.

Li, Q., Osada, M., Mori, K., 2000. Seasonal biochemical variations in Pacific oyster gonadal tissue during sexual maturation. Fisheries science 66, 502-508.

Mark, F.C., Bock, C., Pörtner, H.O., 2002. Oxygen limited thermal tolerance in Antarctic fish investigated by magnetic resonance imaging (MRI) and spectroscopy $\left({ }^{31} \mathrm{P}-\mathrm{MRS}\right)$, Am. J. Physiol. Regul. Integr. Comp. Physiol. 283, 1254- 1262. 
Martoja, R., Martoja-Pierson, M., 1967. Initiation aux techniques de l'histologie animale. Masson et Cie Ed., Paris, 1232 pp.

Seri, S., Watanabe, T., Maita, M., Okamoto, N., Hashigushi, N., Fujimoto, C., Iwai, K., 1995. Application of magnetic resonance imaging to fishes. Nippon Suisan Gakkaishi 61, 331-338.

Shaw, BL., Battle, HI., 1957. The gross and microscopic anatomy of the digestive tract of the oyster Crassotrea virginica (Gmelin). Can. J. Zool. 35, 325-347.

Sokolova, I.M., Bock, C., Pörtner, H.O., 2000. Resistance to freshwater exposure in White Sea Littorina spp II. Acid-base regulation. J. Comp. Physiol. B. 170, 105-115.

Toussaint, C., Fauconneau, B., Medale, F., Collewet, G., Akoka, S., Haffray, P., Davenel, A., 2005. Description of the heterogeneity of lipid distribution in the flesh of brown trout (Salmo trutta) by MR imaging. Aquaculture 243, 255 - 267.

Van Den Berg, C., Van Dusschoten, D., Van As, H., Terlouw, A., Schaafsma, T.J., Osse, J.W.M., 1995. Visualising the water flow in a breathing carp using NMRi. Neth. J. Zool. 45, 338-346.

Van Der Linden, A., Verhoye, M., Pörtner, H.O., Bock, C., 2004. The strengths of in vivo resonance imaging (MRI) to study environmental adaptational physiology in fish. Magma in press.

Wecker, S., Hörnshemeyer, T., Hoehn, M., 2002. Investigation of insect morphology by MRI: Assessment of spatial and temporal resolution. Magn. Reson. Imaging 20, 105-111. 


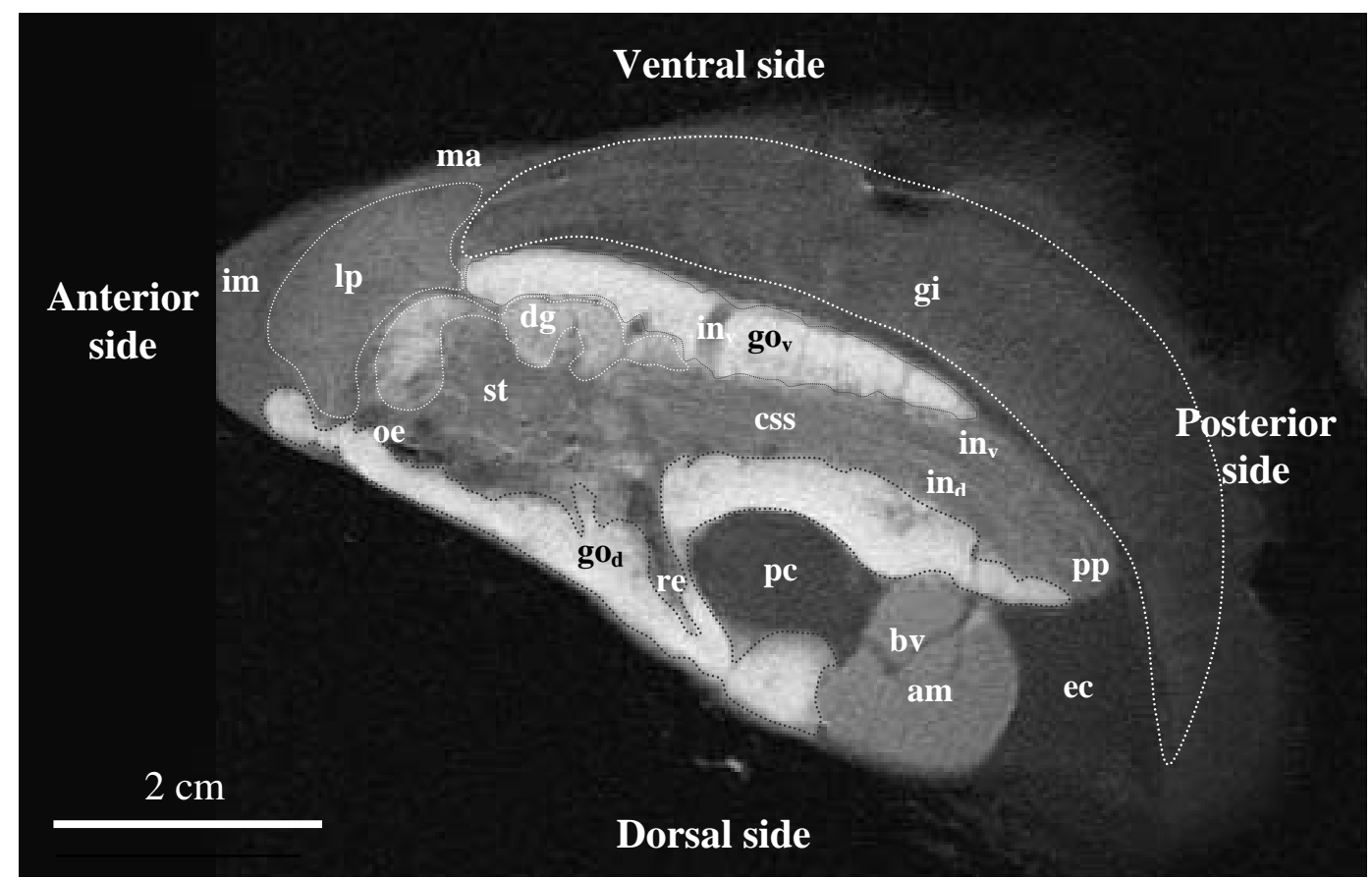

Figure 1: Sagittal $3 \mathrm{~mm}$ slice through the body of the Pacific oyster Crassostrea gigas (spatial in-plane resolution: $230 \mu \mathrm{m}$, see materials and methods for imaging parameters). The main organs and structures clearly identified in this plane are: mantle (ma), isthmus (im), labial palps (lp), gills (gi), intestine (in) and its ventral and dorsal side ( $\left.\mathrm{in}_{\mathrm{V}}, \mathrm{in}_{\mathrm{D}}\right)$, oesophagus (oe), digestive gland (dg), stomach (st), crystalline sac style (css), rectum (re), pyloric process (pp), ventral and dorsal gonads ( $\mathrm{go}_{\mathrm{V}}, \mathrm{go}_{\mathrm{D}}$ ), pericardial cavity (pc), adductor muscle (am), some principal hemolymph sinuses (hs) and the extra-pallial cavity (ec). (see Materials and methods for imaging parameters) 


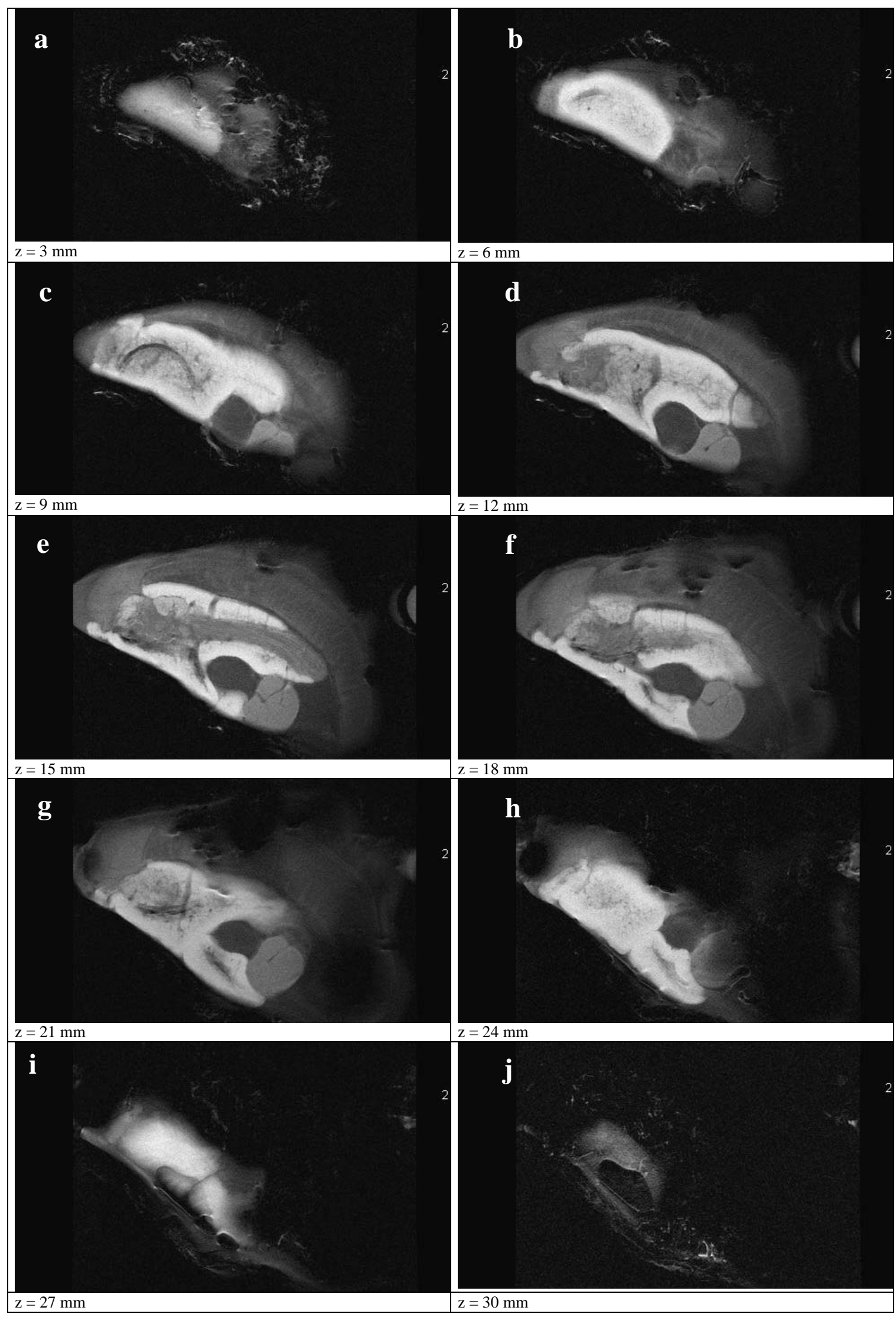

Figure 2: Sagittal multi-slice anatomical images of the soft tissues of the Pacific oyster (see materials and methods for imaging parameters). Layers extended from the right valve (a) to left valve (j). The depth of the slice is indicated by the value of $\mathrm{z}$ in $\mathrm{mm}$. 


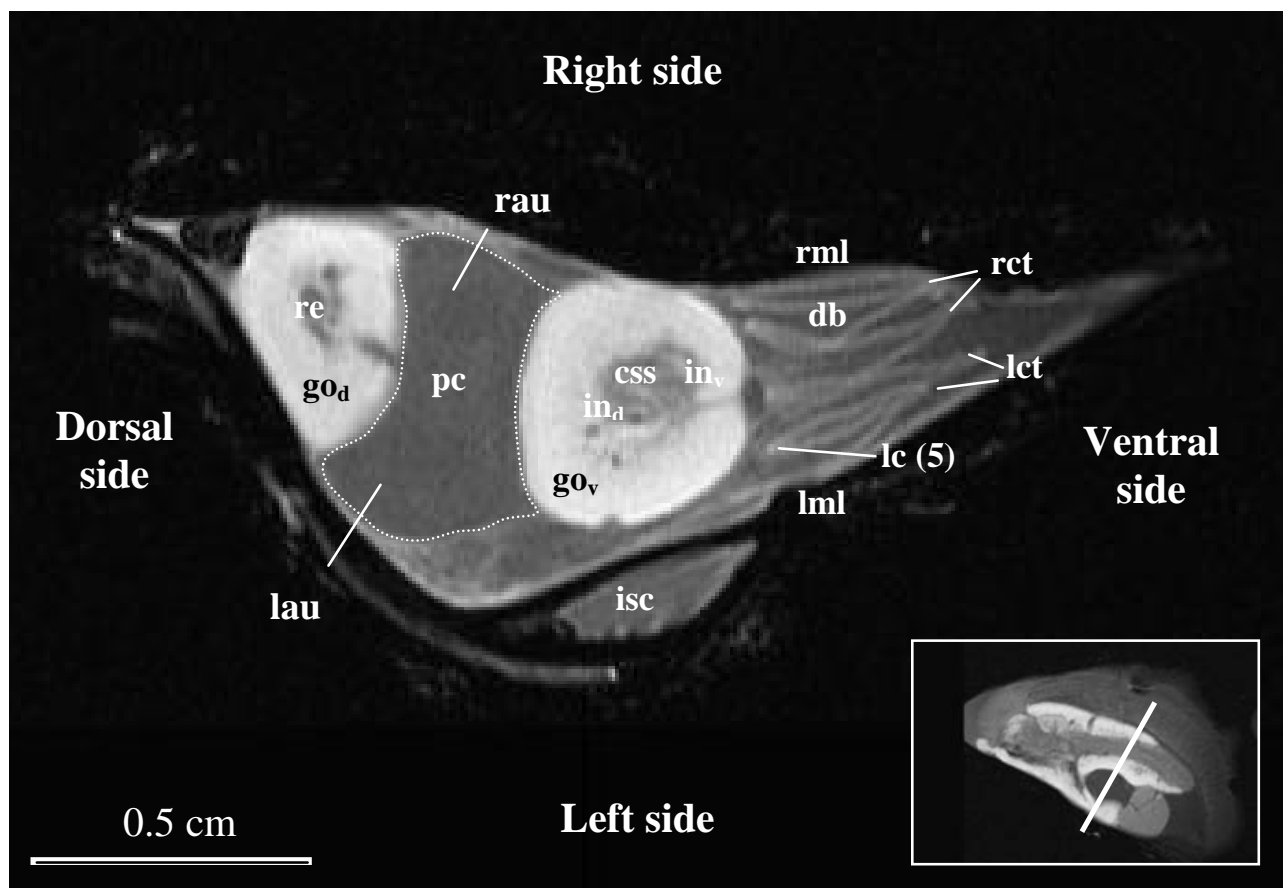

Figure 3: Transversal $3 \mathrm{~mm}$ thin slice through the body of the Pacific oyster (spatial in-plane resolution: $230 \mu \mathrm{m}$, see materials and methods for imaging parameters). The main organs and structures clearly identified in this plane are: demibranchs (db), right and left ctenidia (rct, lct), ventral and dorsal side of the intestine $\left(\mathrm{in}_{\mathrm{V}}, \mathrm{in}_{\mathrm{D}}\right)$, crystalline sac style (css), ventral and dorsal gonads ( $\mathrm{gov}_{\mathrm{V}}$, go $_{\mathrm{D}}$ ), pericardial cavity $(\mathrm{pc})$, right and left lobe of the mantle (rml, lml), longitudinal crests of the gills (lc), and some cavities inside the shell (isc), left and right auricles (lau, rau) can be detected as two rounded thin structures inside the pericardial cavity 


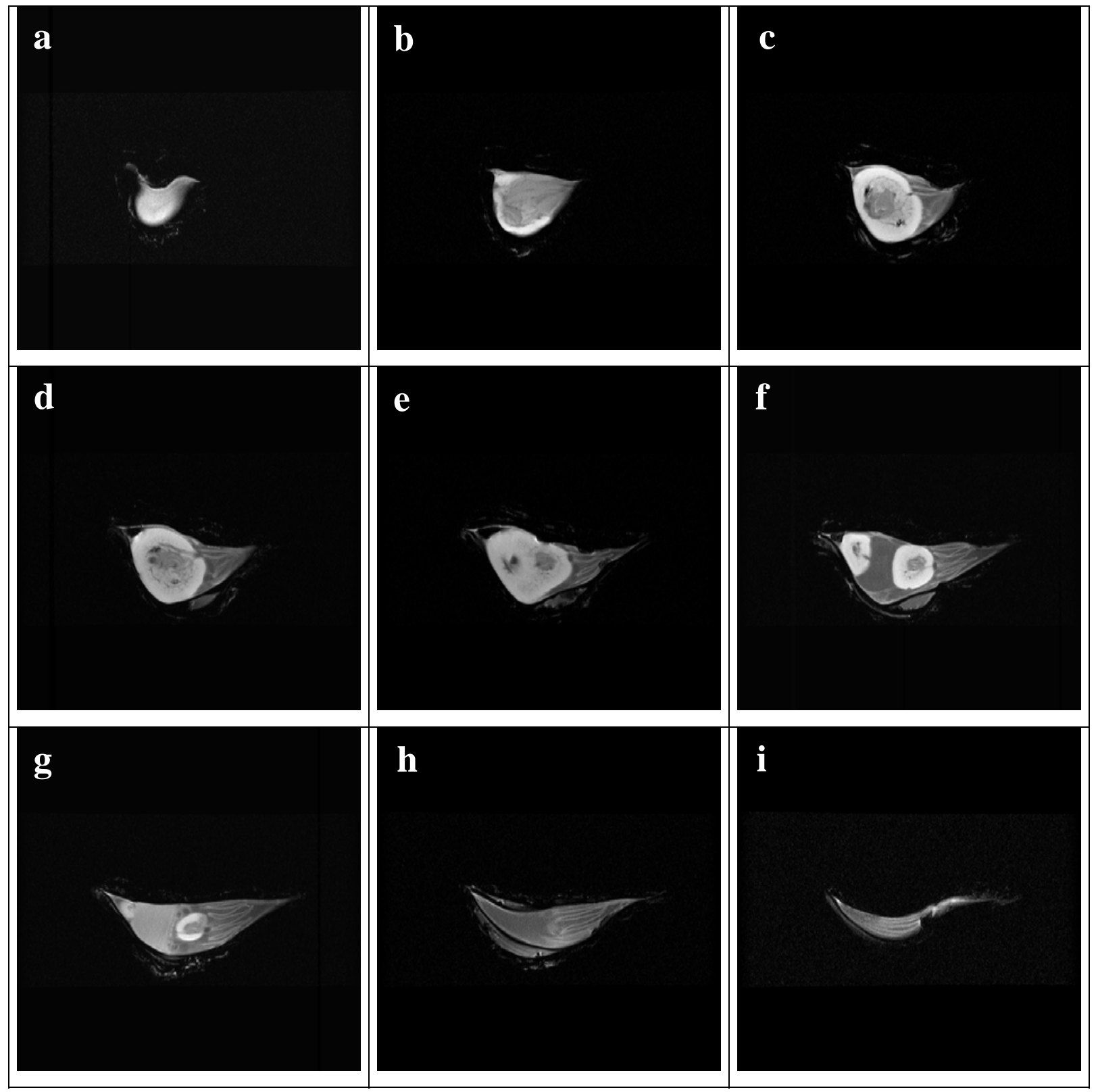

Figure 4: Transversal multi-slice anatomical images of the soft body of the Pacific oyster Crassostrea gigas (see materials and methods for imaging parameters). Slices were chosen to show specific anatomical structures: a: the cephalic hood level; b: the labial palps; c: the stomach level; d: the digestive gland; e: the aorta level; f: the heart; g: the adductor muscle; h: the extra-pallial; i: the mantle. 


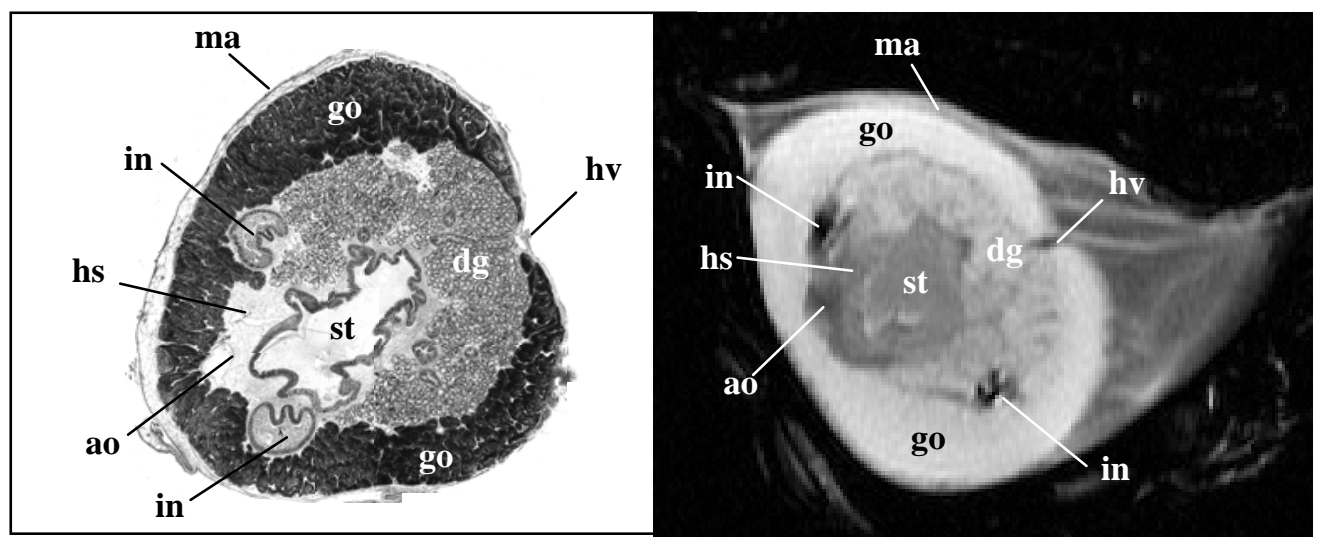

Figure 5: Comparison between MR and conventional microscopy images. Comparison was made on axial images in the anterior part of the body a few $\mathrm{mm}$ above the heart. The correlation with the analogous histologic section, taken from another individual, was very high and comparison of the MR and conventional microscopy images indicates that the main structures and organs in the soft body of oysters are very well represented by MRI. Legend: mantle (ma), intestine (in), digestive gland (dg), stomach (st), gonads (go), aorta (ao) and some main hemolymph sinus (hs) and vessel (hv). Note that the individuals used for this comparison were not the same and the location of this frontal section is presumably not exactly similar between the two methods. 